\title{
Television Exhibition at the Science Museum
}

$\mathrm{T}$ HE choice of the Science Museum, South Kensington, as a venue for the Television Exhibition which was opened there on June 10 is a singularly appropriate one, for not only does it enable an outline of the technical development of television to be well illustrated, but also it will enable the general public to observe and appreciate the value of television as a new form of home entertainment in a manner which is impossible at any commercial demonstration. The Exhibition is to remain open for about three months.

While it is probable that the only way of appre. ciating fully the entertainment value of the new service is by the installation of a receiver in one's own home, yet an endeavour has been made at the Science Museum to enable the general public to observe the broadcast programmes for considerable periods by the installation of eight receivers, one from each of the principal manufacturers. These receivers will be in operation daily from 3 p.m. until 4 p.m., receiving the B.B.C. programme, and they will also be operated at intervals throughout the day by means of a film transmitter which has been specially installed in the Exhibition by Messrs. A. C. Cossor, Ltd., for this purpose.

In the technical section of the Exhibition there is a considerable number of exhibits to illustrate the past and present trends of development. The early work of J. L. Baird is illustrated by several exhibits, and there is a working demonstration of the 30-line television which was broadcast from 1932 until 1935. An important part of this section of the Exhibition is devoted to the development of eathode ray tubes. The old Crookes and Braun tubes are shown in operation, and all the important stages of development of the modern television tube are illustrated by appropriate exhibits.

From the scientific point of view, there can be little doubt that the chief interest is centred around a series of exhibits which have been provided by the Scophony Company, relating to their system of largescreen television. As is indicated in the handbook which has been produced in connexion with the Exhibition, one of the major difficulties of largescreen television is that of controlling a sufficient intensity of light and of projecting it on to the screen. The familiar Kerr cell is practically useless for largescreen television since the optical difficulties and low efficiency are insuperable, even if the cell could be made to operate at the very high frequencies required.

The Scophony system makes use of a patented 'supersonic light control cell' in which the principle of diffraction is employed to control the light intensity. The cell consists of two pieces of glass, between which is a transparent liquid; the beam of light is passed through this liquid. A small plate of piezoelectric quartz is mounted at the base or side of the cell and connected with a source of high-frequency oscillations. The mechanical oscillations thus induced in the quartz crystal produce stress waves in the liquid, which travel through the liquid in a direction transverse to the beam of light with a velocity equal to that of sound in the liquid. The waves in the liquid cause the production of diffraction spectra, the intensity of which is proportional to the intensity of the quartz oscillations. By stopping out the normal ray through the cell and by modulating the quartz oscillations by the incoming television signals, the light in the spectra may be employed to form the television image on the screen.

Used in this simple manner, the supersonic light control would possess no great advantage over the Kerr cell. Its great superiority lies in the fact that, with scanning and optical systems of appropriate design, the velocity of the transverse waves of the cell enables between 402 and 500 elements of the picture to be simultaneously active. With a cell of the Kerr type, only a single elemental area can be active at any instant.

The optical system employed makes use of crossed cylindrical lenses for focusing the light beam, thus making possible the use of very small rotating scanners. The focusing and scanning systems associated with the supersonic light control are radically different in design from any previously used for mechanical systems of television. Space must forbid a description here, but the special features are all illustrated by suitable exhibits.

The Scophony Company's exhibits conclude with two demonstrations of large-screen television, one of which employs a screen measuring 5 feet by 4 feet. The programmes are being transmitted by radio from the Company's laboratories at Campden Hill on a standard of 240 lines, 25 pictures per second.

Another exhibit relating to large-screen television is one provided by the Baird Company of an experimental 'projection cathode ray receiver'. This exhibit comprises a conventional receiver, but instead of reproducing the picture on the fluorescent screen of a large-diameter cathode ray tube, an extremely bright image is reproduced on the screen of quite a small tube. A few inches in front of this tube is fitted a wide-aperture lens which projects an enlarged image on to a ground glass screen placed two feet in front, thus providing an image measuring 18 inches by 12 inches. This type of receiver is only experimental at present, and it is understood that one of the chief difficulties is the short life of the screen of the high-intensity cathode ray tube.

Although the Exhibition gives some indication of a trend towards larger screens, one is forced to wonder if a genuine demand for larger screens exists. Obviously, the larger the screen, the larger is the overall bulk of the apparatus, and, to some extent, the larger is the initial cost and upkeep. If, as seems likely, the future development of television proceeds on the lines of home entertainment, the size and cost of a receiver are of vital importance, and while a small increase in the size of the screen as provided on the present commercial receivers would be an improvement, there is a wide belief amongst owners of receivers that the present size of screen is adequate for home entertainment purposes.

There is, however, a potential field of application for television in the provision of entertainment for large audiences in public halls and cinemas, especially when the broadcasting of important current events becomes a daily feature of the television programmes. For such applications, receivers having the largest possible screens will be required. 